\title{
Pengaruh Interlayer Elektroplating Zinc pada Kekuatan Mekanik Friction Stir Spot Welding Aa1100-Ss400
}

(Effect of Zinc Interlayer Electroplating on Mechanical Properties Friction Stir Spot

Welding Aa1100-Ss400)

\author{
LINGGA ARTI SAPUTRA, NOTA ALI SUKARNO, SITI ZULAEHAH
}

\begin{abstract}
ABSTRAK
Sambungan FSSW dengan material yang berbeda banyak digunakan pada kendaraan. Namun, masalah muncul ketika material tersebut tidak tersambung dengan sempurna. Penggunaan interlayer $\mathrm{Zn}$ mampu meningkatkan kemampuan sambungan. Variasi penggunaan dwell time dan diameter shoulder digunakan untuk memperjelas peranan interlayer electroplating $\mathrm{Zn}$. Pengujian tarik geser yang telah dilakukan membuktikan bahwa penggunaan interlayer electroplating Zn memiliki kemampuan sambungan yang lebih baik. Nilai maksimal pengujian tarik geser sebesar $3.8 \mathrm{kN}$. Nilai maksimal sambungan tanpa interlayer elektroplating $\mathrm{Zn} 2.5 \mathrm{kN}$. Pengujian kekerasan menunjukkan nilai yang lebih besar $63 \mathrm{HV}$ dari pada sambungan tanpa menggunakan interlayer elektroplating $\mathrm{Zn}$.
\end{abstract}

Kata kunci: FSSW, Interlayer Electroplating Zn, Dwell Time, Shoulder.

\section{ABSTRACT}

FSSW joints with different materials are widely used in vehicles. However, problems arise when the materials are not properly joint. The use of Zn interlayer can increase the joint capability. Variations in the use of dwell time and shoulder diameter were used to clarify the role of the $\mathrm{Zn}$ interlayer electroplating. The tensile shear test that has been carried out proves that the use of $\mathrm{Zn}$ interlayer electroplating has a better joint capability. The maximum magnitude of the tensile shear load is $3.8 \mathrm{kN}$. That of joint without $\mathrm{Zn}$ interlayer electroplating $2.5 \mathrm{kN}$. The hardness test showed a greater magnitude of $63 \mathrm{HV}$ than that of joint without using Zn interlayer electroplating

Keywords: FSSW, Interlayer Electroplating Zn, Dwell Time, Shoulder.

\section{PENDAHULUAN}

Pemanasan global yang terjadi saat ini disebabkan oleh peningkatan konsentrasi kadar $\mathrm{C}^{2}$ di atmosfer bumi (You et al., 2020). Gas buang pada sisa pembakaran mesin kendaraan bermotor memberikan pengaruh pada peningkatan $\mathrm{CO}^{2}$ di udara. Industri otomotif mulai mengembangkan teknologi yang ramah lingkungan untuk mengurangi produksi gas buang (Desantes et al., 2020). Efisiensi bahan bakar dapat ditingkatkan dengan menurunkan berat dari material kendaraan bermotor (Kawajiri et al., 2020). Material alumunium memiliki sifat yang ringan sehingga dapat diaplikasikan pada struktur bodi kendaraan bermotor (Zhang et al., 2019; Wang et al., 2015). Performa dari kendaraan bermotor dapat ditingkatkan dengan menggabungkan beberapa logam pada struktur pengelasan (Taub et al., 2019). Pengelasan dengan memadukan beberapa material telah banyak dilakukan, misalnya sambungan Aluminium-steel (Evdokimov et al., 2021), (Uematsu et al., 2020), aluminium-galvanized steel (Yuce et al., 2019), aluminium-magnesium (Jedrasiak \& Shercli, 2019), aluminium-tembaga (Dhara \& Das, 2020).

Friction stir spot welding (FSSW) merupakan metode pengelasan solid-state yang mampu diterapkan pada material beda jenis (dissimilar 
joint) (Suryanarayanan \& Sridhar, 2020). Mazda RX-8 pada tahun 2003 telah menggunakan FSSW untuk pengelasan panel pintu belakang mobil (Piccini \& Svoboda, 2015). Pengelasan material beda jenis (dissimilar joint) pada FSSW akan mengalami penurunan kemampuan karena adanya hook defect. Munculnya hook defect terjadi ketika adanya material yang tidak tersambung sepenuhnya (Li et al., 2014).

Penggunaan interlayer $\mathrm{Zn}$ mampu menurunkan terbentuknya hook defect pada permukaan kedua material (Xu et al., 2015b; Xu et al., 2016). Penelitain ini bertujuan untuk mengetahui pengaruh penggunaan interlayer electroplating $\mathrm{Zn}$ pengelasan friction stir spot welding pada kemampuan mekanik sambungan AA1100 dan SS400.

\section{METODE PENELITIAN}

Tabel 1. menunjukkan dimensi material sambungan FSSW. Posisi material AA1100 berada di atas dan SS400 di bawah. Kecepatan putaran dari tool 1500RPM, plunge deep $1,5 \mathrm{~mm}$. Tabel 2. menunjukkan variasi pengelasan FSSW.

Proses electroplating menggunakan larutan $\mathrm{H}_{2} \mathrm{SO} 4$ (40 g/L), $\mathrm{ZnSO}_{4}(220 \mathrm{~g} / \mathrm{L})$, dan logam Zn murni sebagai anoda. Waktu elektroplating selama 150s, tegangan 1.5 volt, arus 1 Ampere, Aerator. Infrared thermometer digunakan untuk menjaga suhu di bawah $50^{\circ} \mathrm{C}$.
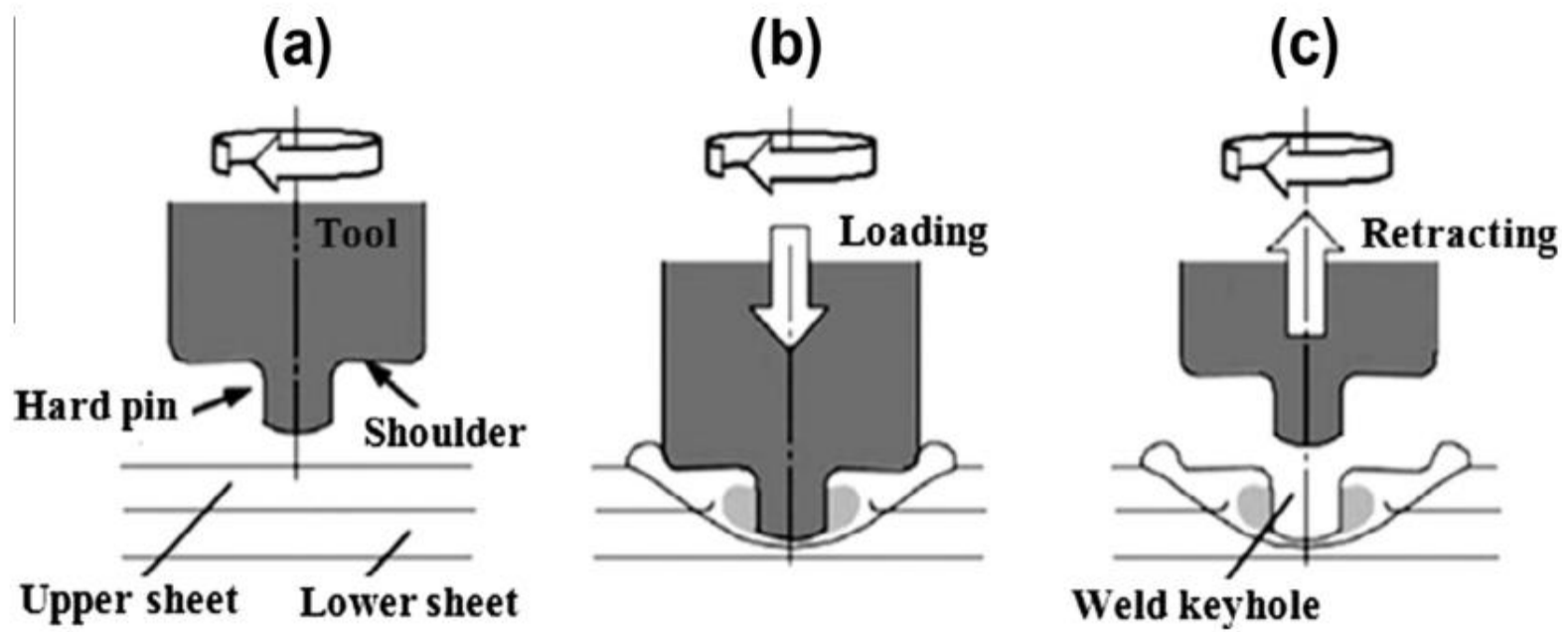

GAMBAR 1. Ilustrasi proses FSSW (a) plunging; (b) bonding; (c) drawing out

(Sumber: Wang et al., 2007)

TABEL 1. Dimensi Material FSSW

\begin{tabular}{cccc}
\hline Material & Wide $(\mathbf{m m})$ & Hight. $(\mathbf{m m})$ & Thicknes $(\mathbf{m m})$ \\
\hline Al 1100 & 3.5 & 10 & 3 \\
SS 400 & 3.5 & 10 & 1 \\
\hline
\end{tabular}

TABEL 2. Parameter Pengelasan FSSW

\begin{tabular}{ccc}
\hline Variasi & Dweel time $(\mathbf{s})$ & Ø Shoulder $(\mathbf{m m})$ \\
\hline Dengan interlayer & $2,4,6,8$ & 12,18 \\
Tanpa interlayer & $2,4,6,8$ & 12,18 \\
\hline
\end{tabular}


Proses elektroplating dihentikan ketika suhu permukaan larutan melebihi $50^{\circ} \mathrm{C}$. Aerator digunakan selama proses electroplating berlangsung. Specimen SS400 sebelumnya dibersihkan terlebih dahulu menggunakan alkohol $70 \%$ dan selanjutnya dilakukan proses elektroplating. Gambar 3 menunjukkan desain alat pencengkram sambungan FSSW. Gambar 4 menunjukkan proses elektroplating spesimen SS400 FSSW sebelum dilakukan proses pengelasan. Pengujian tarik geser menggunakan Universal testing machine, pengujian kekerasan menggunakan Micro Vickers dengan standar ASTM E384.

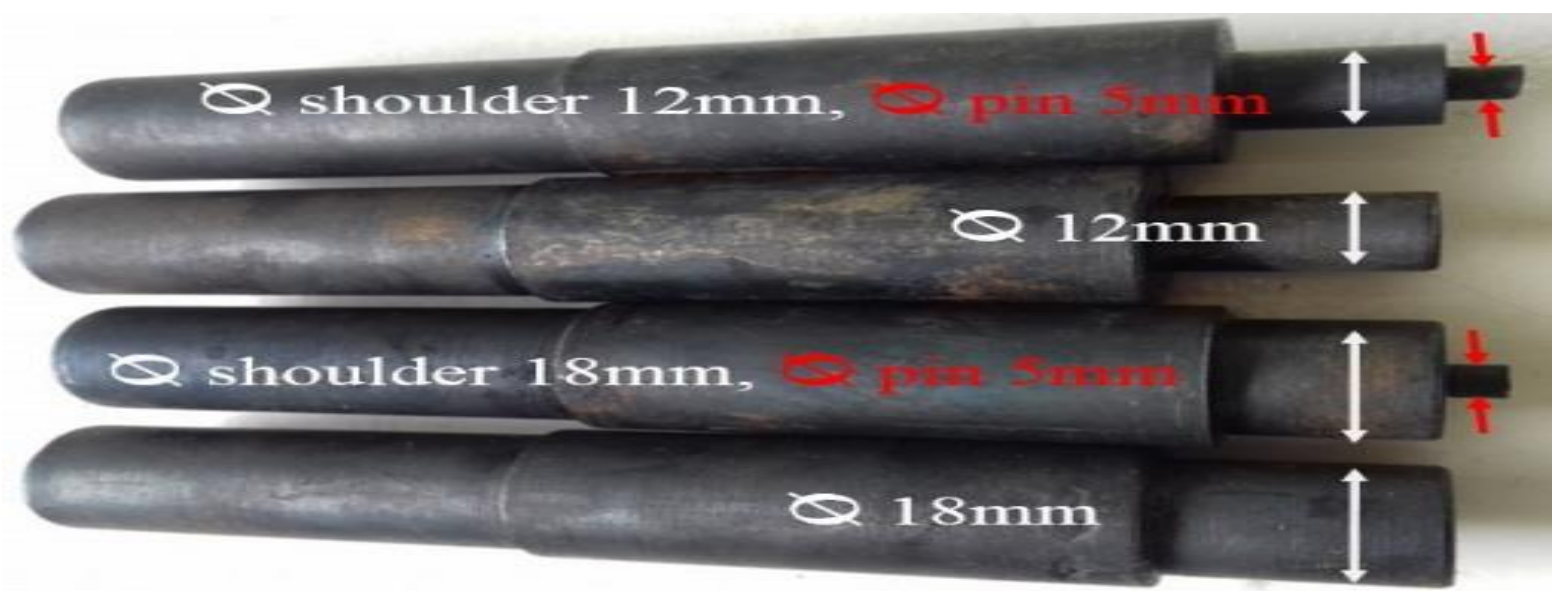

GAMBAR 2. Toll FSSW

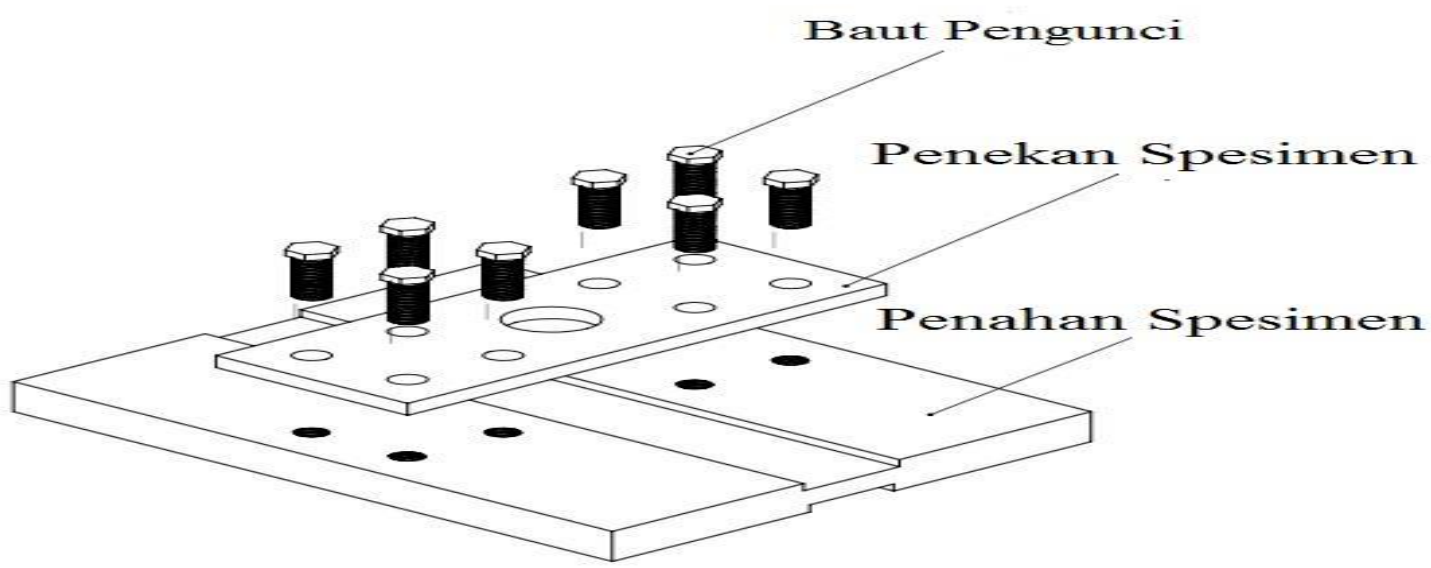

Gambar 3. Alat Pencengkram Sambungan FSSW

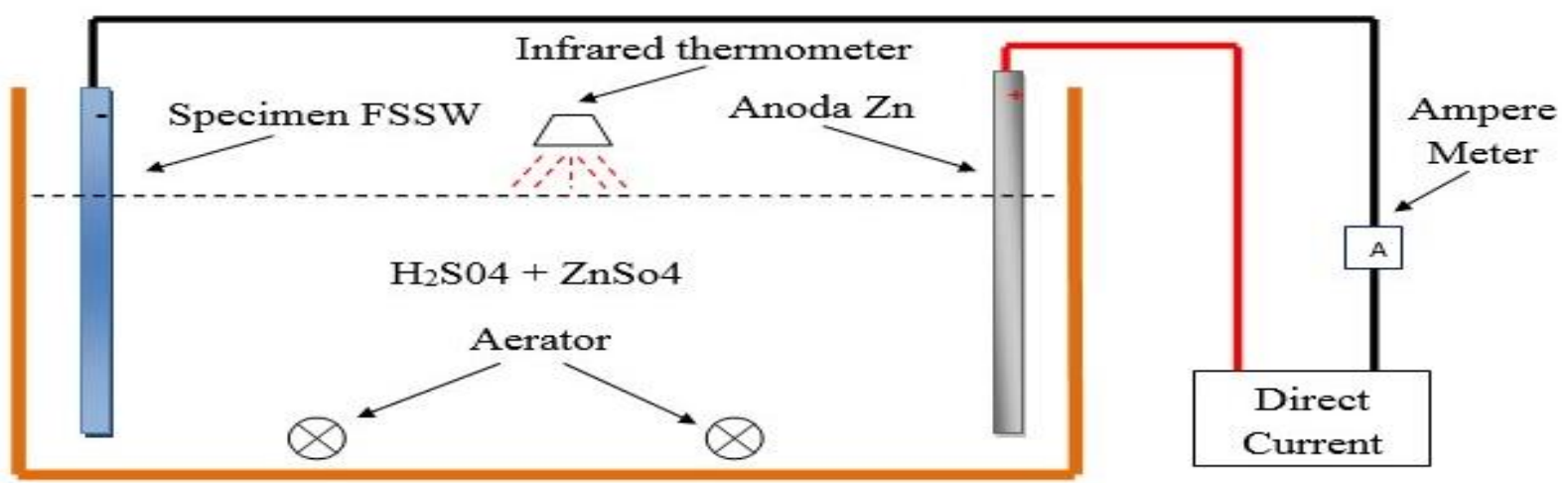

GAMBAR 4. Proses Elektroplating FSSW 


\section{HASIL DAN PEMBAHASAN}

\section{Hasil Pengujian Tarik}

Interlayer yang diberikan pada spesimen pengelasan FSSW memberikan pengaruh pada hasil sambungan. Gambar 5 menunjukkan hasil pengujian tarik pada pengelasan FSSW dengan interlayer. Variasi dwell time memberikan nilai pengujian yang berbeda. Dwell time 2 s dengan nilai $2,5 \mathrm{kN}$ dan dwell time $8 \mathrm{~s}$ dengan nilai $3,8 \mathrm{kN}$. penambahan interlayer $\mathrm{Zn}$ peningkatan dwell time berpengaruh pada peningkatan kekuatan sambungan. Penggunaan interlayer $\mathrm{Zn}$ mampu menurunkan terbentuknya cacat hook pada celah dua material. Hal itu terjadi karena panas yang masuk lebih lama menyebabkan material dan interlayer $\mathrm{Zn}$ menjadi lunak sehingga mampu membentuk ikatan yang lebih merata pada permukaan sambungan (Lin et al., 2012, Bilici et al., 2011).
Gambar 6 menunjukkan hasil pengujian tarik geser FSSW tanpa interlayer. Pada pengelasan FSSW dengan variasi dwell time tanpa menggunakan interlayer $\mathrm{Zn}$ memiliki kecenderungan tidak terjadi peningkatan kemampuan sambungan (Nugroho et al., 2020). Hasil pengujian tertinggi pada dwell time $8 \mathrm{~s}$ memiliki nilai $3,8 \mathrm{kN}$ dan nilai pengujian terendah pada dwell time $2 \mathrm{~s}$ dengan nilai $1,8 \mathrm{kN}$. Penggunaan variasi yang berbeda pada shoulder memiliki pengaruh pada hasil pengelasan (Lin \& Chen, 2015). Peningkatan diameter shoulder pada variasi FSSW dengan interlayer dan tanpa interlayer menunjukkan kenaikan kemampuan sambungan yang signifikan. Penelitian FSSW dengan memberikan interlayer $\mathrm{Zn}$ telah banyak dilakukan. Inovasi sambungan FSSW telah banyak dilakukan. Tabel 3 menunjukkan rangkuman hasil pengelasan FSSW dengan menambahkan interlayer $\mathrm{Zn}$.

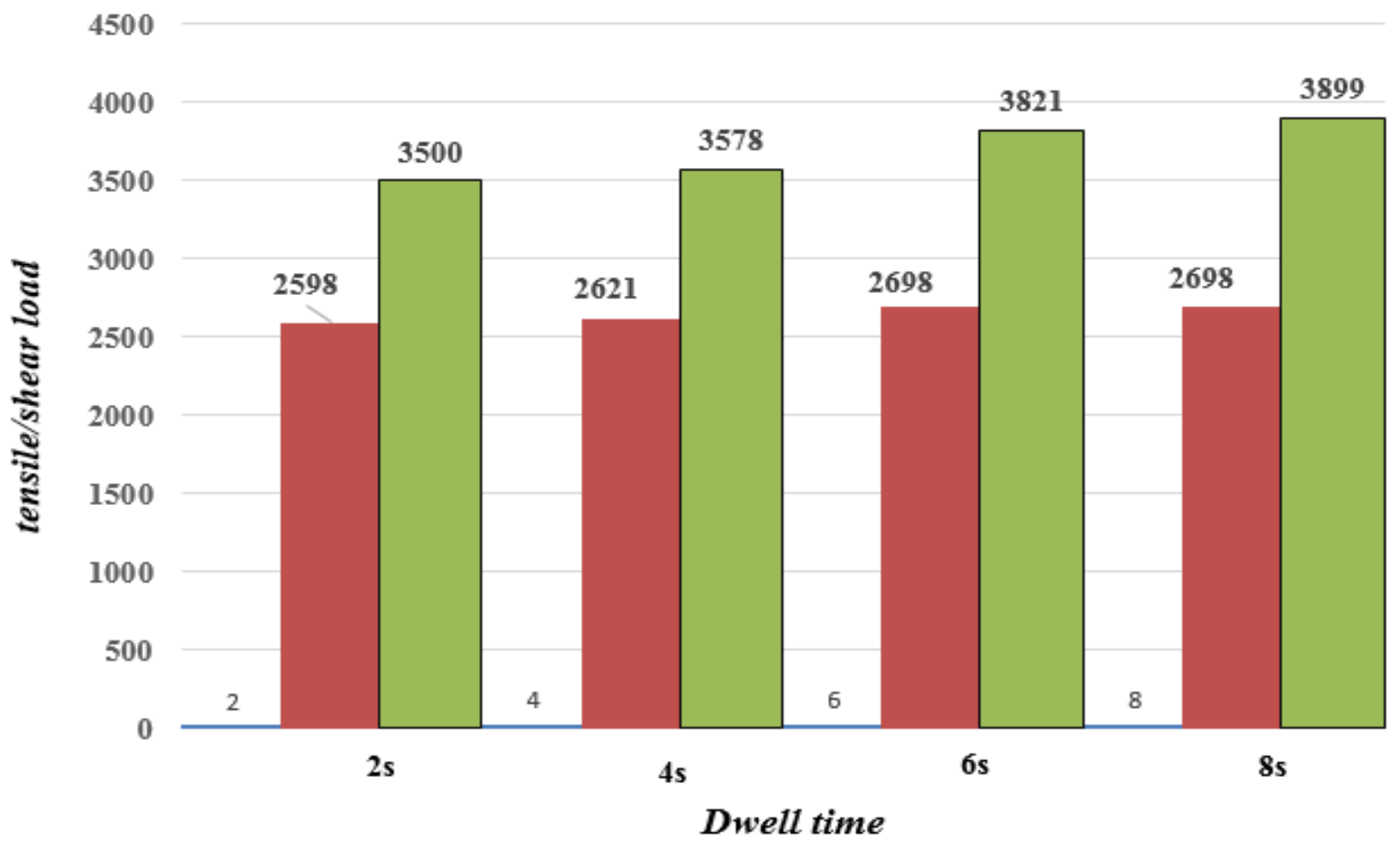

$\varnothing$ shoulder $12 \mathrm{~mm}$ 


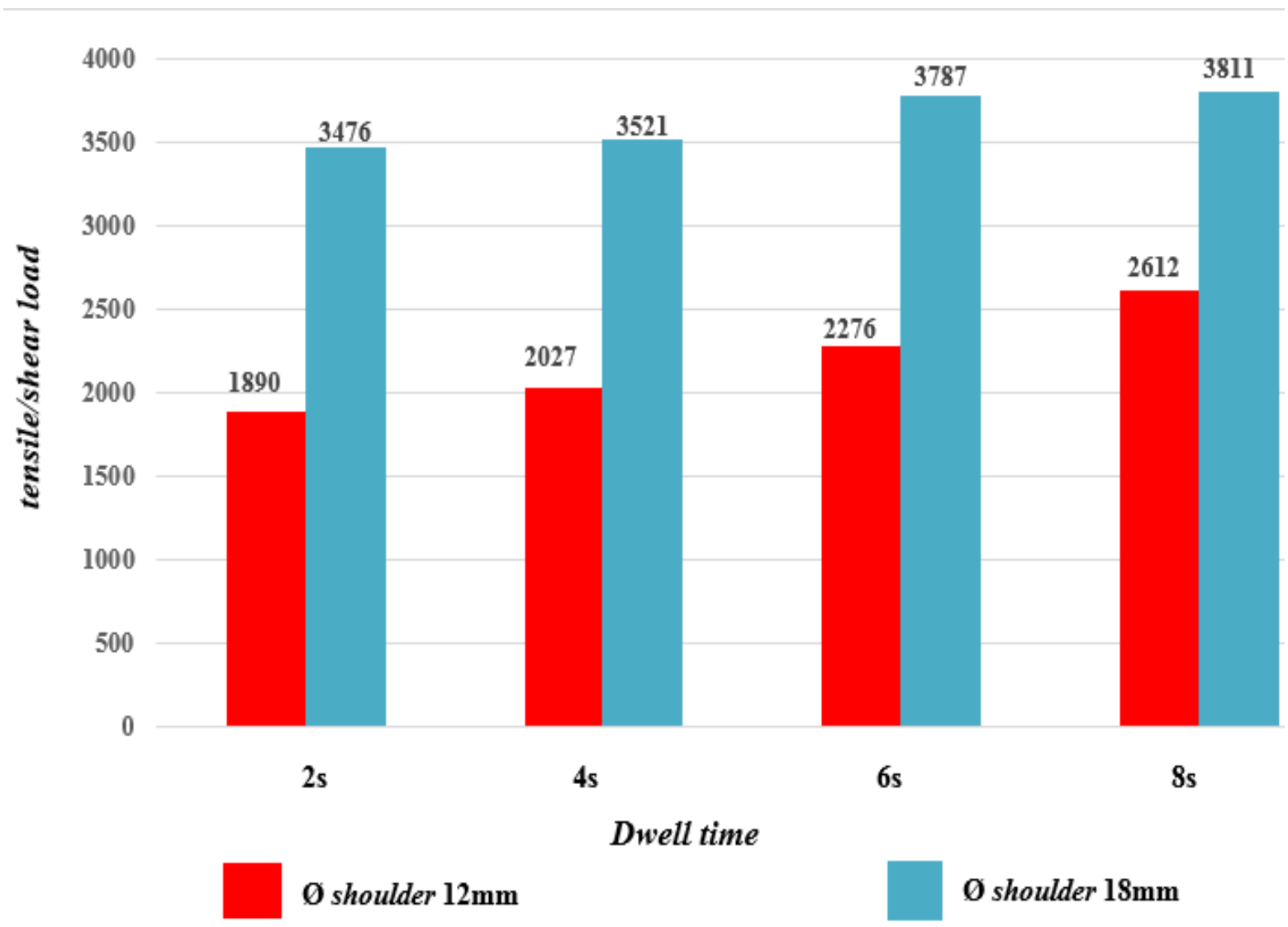

GAMBAR 6. Hasil Pengujian Tarik Geser FSSW Tanpa Interlayer

TABEL 3. Ringkasan Data Hasil Pengujian Tarik FSSW Dengan Interlayer Zn

\begin{tabular}{|c|c|c|c|c|}
\hline & $\begin{array}{l}\text { Ketebalan } \\
\quad(\mathbf{m m})\end{array}$ & Variasi sambungan & Maximum load (kN) & $\operatorname{Refs}$ \\
\hline AZ280-AZ80 & 2.4 & Pin silinder & $4.1,2.4$ & (Xu et al., 2015) \\
\hline AZ280-AZ80 & 2.4 & Pin silinder & $4.0,1.9$ & (Xu et al., 2015) \\
\hline AZ31-AZ80 & 2.4 & Pin silinder & $3.9,1.8$ & (Xu et al., 2015) \\
\hline AA1100-AA1100 & 1.8 & $\begin{array}{l}\text { Partikel Zn, dwell time } \\
\quad 5,10,15,20 \mathrm{~s}\end{array}$ & 4.5 & (Saputra et al., 2021) \\
\hline AA1100-AA1100 & 1.8 & $\begin{array}{l}\text { Partikel Zn, dwell time } \\
20,30,40,50 \mathrm{~s}\end{array}$ & 3.8 & $\begin{array}{c}\text { (Arti Saputra et al., } \\
\text { 2018) }\end{array}$ \\
\hline AZ31- AZ31 & 2.4 & $\begin{array}{c}\text { Lembaran interlayer } \mathrm{Zn} \\
(0.16,0.12,0.08,0.04)\end{array}$ & $4.1,5.2,4.6,4.2,2.7$ & (Xu et al., 2015) \\
\hline $\mathrm{Cu}-\mathrm{Al}$ & $5-2$ & $\begin{array}{c}\text { Lembaran Zn, P1.5, } \\
\text { P2.5, P6, P6 } \\
\text { (Zn 0.05mm) }\end{array}$ & $2.8,3.4,4.6,4,1$ & $\begin{array}{c}\text { (Boucherit \& Taillard, } \\
\text { 2017) }\end{array}$ \\
\hline
\end{tabular}




\section{Hasil Pengujian Kekerasan}

Pengujian dilakukan pada permukaan pada daerah pengelasan sambungan. Gambar 7 menunjukkan daerah dimana dilakukan pengujian kekerasan.

Gambar 7. Menunjukkan hasil pengujian micro Vikers FSSW dengan interlayer Zn. Pengujian dilakukan dimulai dari pusat keyhole. Hasil pengujian pada dwell time 2 s memiliki nilai kekerasan maksimal $59 \mathrm{HV}$ dan nilai minimal 39HV. Nilai maksimal pada dwell time $8 \mathrm{~s}$ adalah $63 \mathrm{HV}$ dan nilai terendah $39 \mathrm{HV}$.
Kecenderungan penurunan tingkat kekerasan disebabkan oleh terbentuknya senyawa intermetalik parsial dan terjadinya proses aging akibat kenaikan suhu (Zhang et al., 2015). Gambar 8 menunjukkan hasil pengujian micro vikers FSSW tanpa interlayer $\mathrm{Zn}$. Pengujian yang dilakukan tingkat persebaran membentuk $W$-shape (Venukumar et al., 2014). Secara keseluruhan dwell time $2 \mathrm{~s}$ memiliki nilai terendah dan pada dwell time 8s memiliki rentang tingkat distribusi kekerasan yang lebih besar.

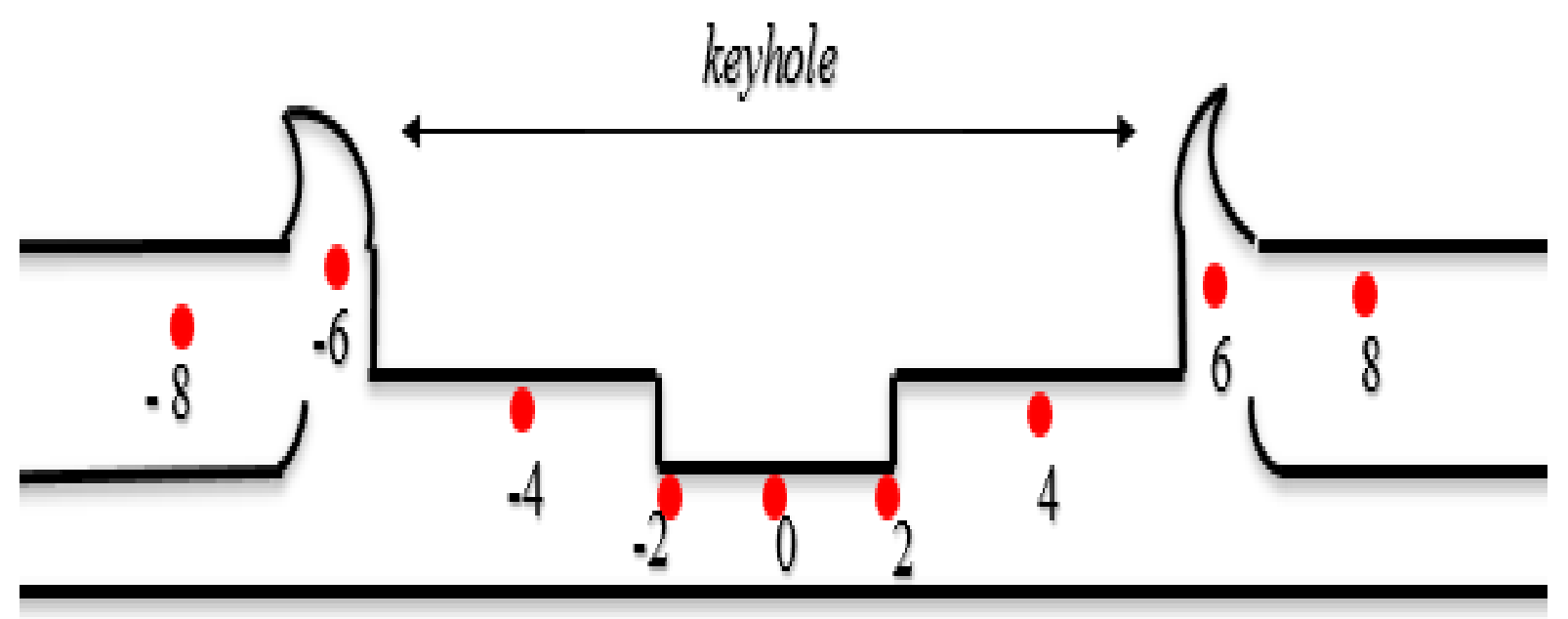

Gambar 7. Posisi Penetrasi Micro Vikers

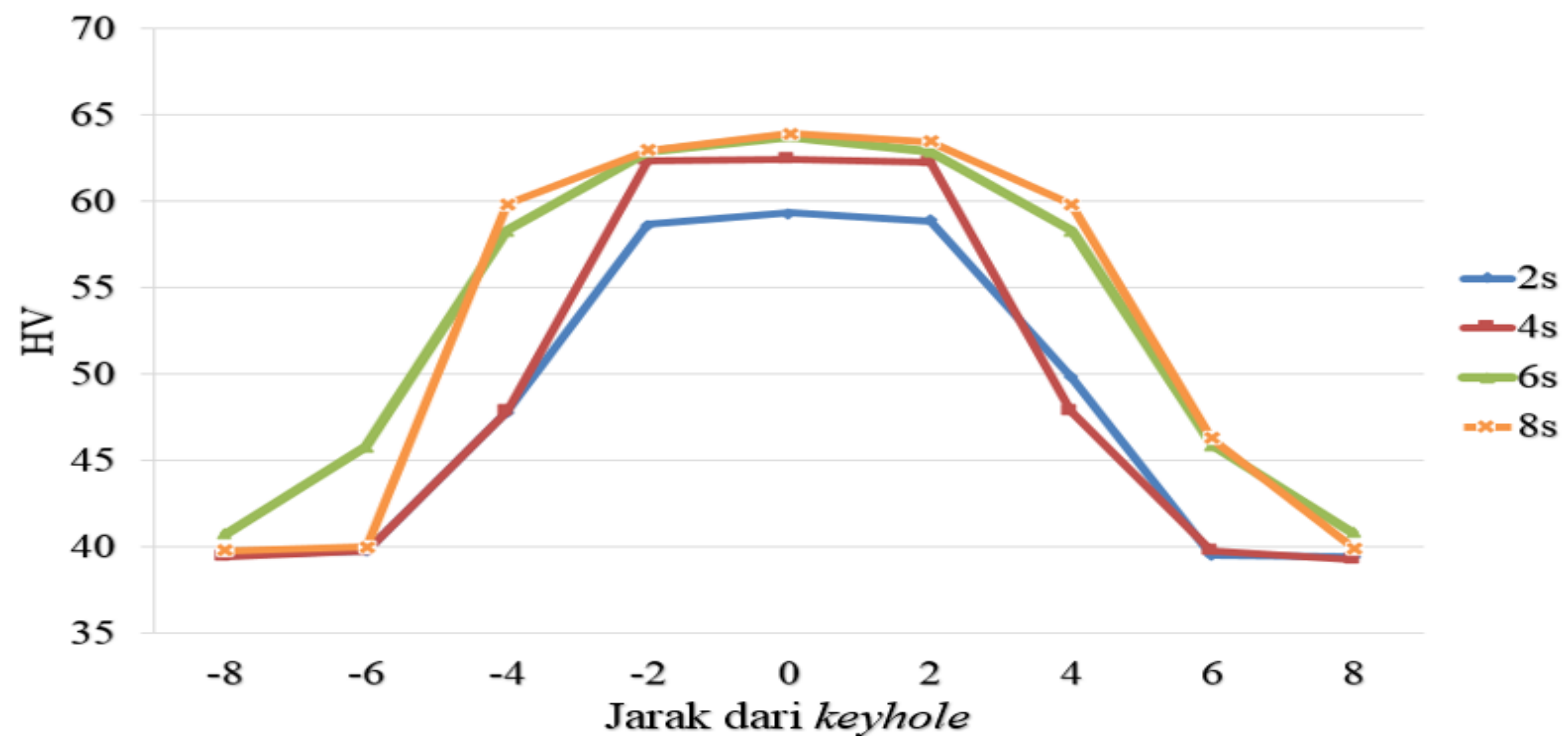

GAMBAR 8. Hasil Pengujian Micro Vikers FSSW Dengan Interlayer Zn 


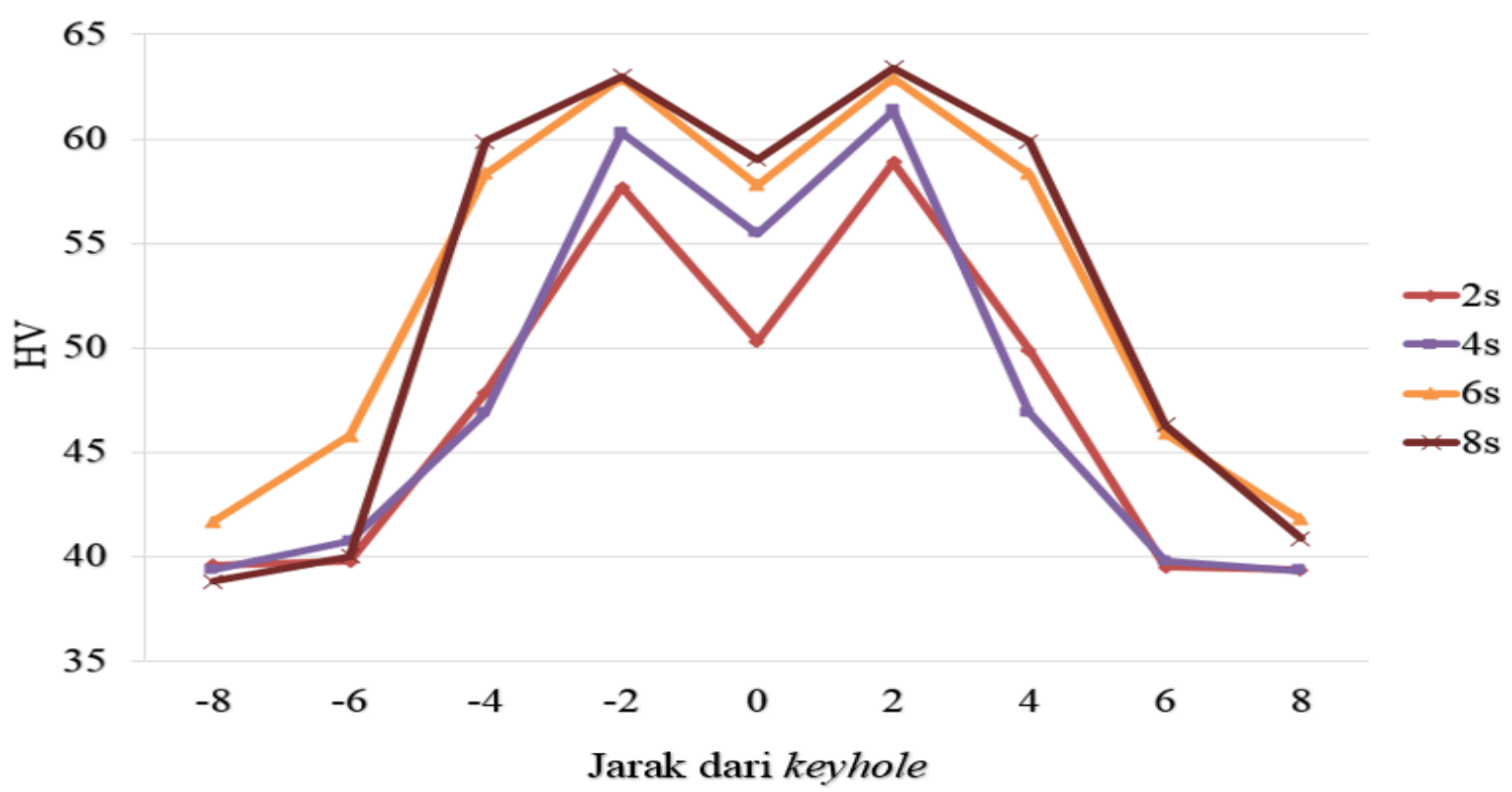

GAMBAR 9. Hasil Pengujian Micro Vikers FSSW Tanpa Interlayer Zn

\section{KESIMPULAN}

Dalam penelitian ini, pengaruh penggunaan interlayer elektroplating $\mathrm{Zn}$ pada material AA1100-SS400 pada sifat mekanik memiliki peranan yang signifikan. Dari hasil pengujian didapat hasil sebagai berikut:

Hasil pengujian tarik geser membuktikan bahwa kemampuan sambungan FSSW dengan interlayer elektroplating $\mathrm{Zn}$ lebih besar $(3,8 \mathrm{kN})$ dari pada sambungan tanpa interlayer elektroplating $\mathrm{Zn}(2,5 \mathrm{kN})$. Hasil pengujian kekerasan sambungan FSSW dengan elektroplating dengan interlayer elektroplating $\mathrm{Zn}$ memiliki tingkat distribusi nilai kekerasan yang lebih tinggi $63 \mathrm{HV}$ dan nilai terendah $38 \mathrm{HV}$ pada dwell time $8 \mathrm{~s}$.

\section{UCAPAN TERIMA KASIH}

Terima kasih kepada Direktorat Riset dan Pengabdian Masyarakat, Direktorat Jenderal Riset dan Pengembangan Kementerian Riset, Teknologi, dan Pendidikan Tinggi Republik Indonesia yang telah mendanai penelitian ini melalui program Penelitian Dosen Pemula tahun pelaksanaan 2021 dengan nomor kontrak 067/E4.1/AK.04.PT/2021

\section{DAFTAR PUSTAKA}

Arti Saputra, L., Muhayat, N., \& Triyono, T. (2018). Effect of Zn interlayer particles on mechanical properties and microstructure of friction stir spot welding aluminum alloy. MATEC Web of Conferences, 218, 1-6.

https://doi.org/10.1051/matecconf/20182 1804005

Bilici, M. K., Irfan, A., \& Kurtulmus, M. (2011). The optimization of welding parameters for friction stir spot welding of high density polyethylene sheets. Materials \& Design, 32(7), 4074-4079. https://doi.org/10.1016/j.matdes.2011.03. 014

Boucherit, A., \& Taillard, R. (2017). Effect of a $\mathrm{Zn}$ interlayer on dissimilar FSSW of $\mathrm{Al}$ and $\mathrm{Cu}$. Materials \& Design. https://doi.org/10.1016/j.matdes.2017.03. 063

Desantes, J. M., Molina, S., \& Novella, R. (2020). Comparative global warming impact and NO $X$ emissions of conventional and hydrogen automotive propulsion systems. Energy Conversion and Management, 221, 113137. https://doi.org/10.1016/j.enconman.2020. 113137 
Dhara, S., \& Das, A. (2020). Impact of ultrasonic welding on multi-layered $\mathrm{Al}-$ $\mathrm{Cu}$ joint for electric vehicle battery applications: A layer-wise microstructural analysis. Materials Science \& Engineering: $\quad A, \quad 791,139795$. https://doi.org/10.1016/j.msea.2020.1397 95

Evdokimov, A., Doynov, N., Ossenbrink, R., Obrosov, A., \& Weiß, S. (2021). Thermomechanical laser welding simulation of dissimilar steel-aluminum overlap joints. International Journal of Mechanical Sciences, 190, 106019. https://doi.org/10.1016/j.ijmecsci.2020.1 06019

Jedrasiak, P., \& Shercli, H. R. (2019). Small strain fi nite element modelling of friction stir spot welding of $\mathrm{Al}$ and $\mathrm{Mg}$ alloys. Journal of Materials Processing Technology, 263, 207-222. https://doi.org/10.1016/j.jmatprotec.2018. 07.031

Kawajiri, K., Kobayashi, M., \& Sakamoto, K. (2020). Lightweight materials equal lightweight greenhouse gas emissions ?: A historical analysis of greenhouse gases of vehicle material substitution. Journal of Cleaner Production, 253, 119805. https://doi.org/10.1016/j.jclepro.2019.119 805

Li, W., Li, J., Zhang, Z., Gao, D., Wang, W., \& Dong, C. (2014). Improving mechanical properties of pinless friction stir spot welded joints by eliminating hook defect. Materials and Design, 62, 247-254. https://doi.org/10.1016/j.matdes.2014.05. 028

Lin, Y., \& Chen, J. (2015). Journal of Materials Processing Technology Influence of process parameters on friction stir spot welded aluminum joints by various threaded tools. Journal of Materials Processing Technology, 225, 347-356. https://doi.org/10.1016/j.jmatprotec.2015. 06.024

Lin, Y., Liu, J., Lin, B., Lin, C., \& Tsai, H. (2012). Effects of process parameters on strength of $\mathrm{Mg}$ alloy AZ61 friction stir spot welds. Journal of Materials \& Design, 35, 350-357. https://doi.org/10.1016/j.matdes.2011.08. 050
Nugroho, A. W., Purnomo, F. H., \& Rahman, M. B. N. (2021). Karakterisasi sambungan friction stir spot welding pada plat aluminium 5083. Semesta Teknika, 24(1), 34-46.

https://doi.org/10.18196/st.v24i1.12603

Piccini, J. M., \& Svoboda, H. G. (2015). Effect of the tool penetration depth in Friction Stir Spot Welding ( FSSW ) of dissimilar aluminum alloys. Procedia Materials Science, $\quad 8, \quad 868-877$. https://doi.org/10.1016/j.mspro.2015.04.1 47

Saputra, L. A. (2021). Pengaruh interlayer Zn pada kekuatan mekanik sambungan friction stir spot welding material aluminium paduan. Perwira Journal of Science and Engineering (PJSE), 1(1), 100-105.

Suryanarayanan, R., \& Sridhar, V. G. (2020). Materials Today: Proceedings Studies on the influence of process parameters in friction stir spot welded joints - A review. Materials Today: Proceedings, 37(2), 2695-2702.

https://doi.org/10.1016/j.matpr.2020.08.5 32

Taub, A., Moor, E. D., Luo, A., Matlock, D. K., Speer, J. G., \& Vaidya, U. (2019). Materials for automotive lightweighting. Annual Review of Materials Research, 49, 327-359. https://doi.org/10.1146/annurevmatsci-070218-010134

Uematsu, Y., Kakiuchi, T., Ogawa, D., \& Hashiba, K. (2020). Fatigue crack propagation near the interface between $\mathrm{Al}$ and steel in dissimilar $\mathrm{Al} /$ steel friction stir welds. International Journal of Fatigue, 138, 105706. https://doi.org/10.1016/j.ijfatigue.2020.1 05706

Venukumar, S., Baby, B., Muthukumaran, S., \& Kailas, S. V. (2014). Microstructural and mechanical properties of walking friction stir spot welded AA 6061-T6 sheets. Procedia Materials Science, 6(Icmpc), 656-665. https://doi.org/10.1016/j.mspro.2014.07.0 81

Wang, B., Lei, B. B., Zhu, J. X., Feng, Q., Wang, L., \& Wu, D. (2015). EBSD study on microstructure and texture of friction stir welded AA5052-O and AA6061-T6 
dissimilar joint. Materials and Design, 87, 593-599.

https://doi.org/10.1016/j.matdes.2015.08. 060

Wang, D., \& Lee, S. C. (2007). Microstructures and failure mechanisms of friction stir spot welds of aluminum 6061-T6 sheets. 186. Journal of Materials Processing Technology, 186(1-3), 291-297. https://doi.org/10.1016/j.jmatprotec. 2006. 12.045

Xu, R. Z., Ni, D. R., Yang, Q., Liu, C. Z., \& Ma, Z. Y. (2015a). Influence of $\mathrm{Zn}$ interlayer addition on microstructure and mechanical properties of friction stir welded AZ31 Mg alloy. Journal of Materials Science, 4160-4173. https://doi.org/10.1007/s10853-0158841-3

Xu, R. Z., Ni, D. R., Yang, Q., Liu, C. Z., \& Ma, Z. Y. (2015b). Influencing mechanism of $\mathrm{Zn}$ interlayer addition on hook defects of friction stir spot welded $\mathrm{Mg}-\mathrm{Al}-\mathrm{Zn}$ alloy joints. Materials \& Design, 69, 163169.

https://doi.org/10.1016/j.matdes.2014.12. 045

Xu, R. Z., Ni, D. R., Yang, Q., Liu, C. Z., \& Ma, Z. Y. (2016). Pinless friction stir spot welding of $\mathrm{Mg}-3 \mathrm{Al}-1 \mathrm{Zn}$ alloy with $\mathrm{Zn}$ interlayer. Journal of Materials Science \& Technology. 32(1), 76-88. https://doi.org/10.1016/j.jmst.2015.08.01 2

You, Q., Wu, F., Shen, L., Pepin, N., Jiang, Z., \& Kang, S. (2020). Tibetan Plateau ampli fication of climate extremes under global warming of. Global and Planetary Change, 192, 103261. https://doi.org/10.1016/j.gloplacha.2020. 103261

Yuce, C., Karpat, F., \& Yavuz, N. (2019). Investigations on the microstructure and mechanical properties of laser welded dissimilar galvanized steel - aluminum joints. The International Journal of Advanced Manufacturing Technology, 104, 2693-2704. https://doi.org/10.1007/s00170-01904154-7

Zhang, B., Chen, X., Pan, K., \& Yang, C. (2019). J-integral based correlation evaluation between microstructure and mechanical strength for FSSW joints made of automotive aluminum alloys. Journal of Manufacturing Processes, 44, 62-71.

https://doi.org/10.1016/j.jmapro.2019.05. 039

Zhang, Z., Xiao, B. L., \& Ma, Z. Y. (2015). Enhancing mechanical properties of friction stir welded 2219Al-T6 joints at high welding speed through water cooling and post-welding arti fi cial ageing. Materials Characterization, 106, 255265. https://doi.org/10.1016/j.matchar.2015.06 .003

PENULIS:

Lingga Arti Saputra

Program Studi Teknik Mesin, Fakultas Sains dan Teknik, Universitas Perwira Purbalingga. Jalan Latjend. S. Parman No. 50, Penambongan, Purbalingga

Email: linggaarti@unperba.ac.id

\section{Nota Ali Sukarno}

Program Studi Teknik Mesin, Fakultas Sains dan Teknik, Universitas Perwira Purbalingga. Jalan Latjend. S. Parman No. 50, Penambongan, Purbalingga

Email: notalisukarno@unperba.ac.id

Siti Zulaehah

Program Studi Teknik Mesin, Fakultas Sains dan Teknik, Universitas Perwira Purbalingga. Jalan Latjend. S. Parman No. 50, Penambongan, Purbalingga

Email: s.zulaehah@unperba.ac.id 